Discussion

Previous work has suggested that estimating total palmitic acid is a useful method of assessing lecithin concentration in amniotic fluid. This is supported by the data contained in the graph of palmitic acid levels at different gestational ages (fig. 3) which is similar to the data of Gluck et al. (1971) on the variation of lecithin concentration with maturity. They both show rapid increases between 34 and 38 weeks' gestation and then a decline towands full term. Though the plot of lecithan concentration shows some increase beginning at 25 weeks' gestation, the level of palmitic acid does not rise at all until 35 weeks. This difference is most probably because the lecithin produced before 34 weeks is palmitoyl-myristoyl lecithin (Gluck et al., 1971) and our measurement of palmitic acid would be less sensitive to changes in concentration of this substance. However, this is no disadvantage, since surfactant containing the palmitoyl-myristoyl lecithin is often ineffective in sustaining normal pulmonary function and it is the increase in dipalmitoyl lecithin at 35 weeks which is really important.

A comparison of the level of lecithin which Bhagwanani, et al. (1972) gave as an indication of lung maturity and the critical palmitic acid concentration suggested by the present study gives funther confirmation of the validity of palmitic acid measurements in assessing liquor lecithin levels. By measuring lecithin phosphorus, Bhagwanani found that levels of lecithin above $3.5 \mathrm{mg} / 100 \mathrm{ml}$ signified lung maturity. The lowest concentration of palmitic acid that we found in a specimen of liquor from a mature pregnancy was 0.073 $\mathrm{mmol} / \mathrm{l}$. If one assumes that this all comes from dipalmitoyl lecithin it corresponds to a lecithin concentration of 3.48 $\mathrm{mg} / 100 \mathrm{ml}$. This supports our experimental findings that most palmitic acid in amniotic fluid originates from lecithin (Warren et al. 1974).

There is now much evidence that measuring the total palmitic acid concentration of liquor provides a good assessment of fetal lung maturity. There was a clear division between cases in which R.D.S. developed and our mature samples, and good agreement between the new method and the L/S ratio. The main advantage of measuring palmitic acid is the speed and simplicity of the method. Four specimens can be processed and the results obtained in one hour. The fact that it is quantitative is another possible advantage. This could be panticularly valuable in borderline cases, where more than one liquor may be investigated to determine the trend in lecithin level, but this has yet to be shown in practice. The possibility that the degree of severity of R.D.S. could be predicted from the liquor palmitic acid level is also being examined.

We are greatly indebted to our obstetric and paediatric colleagues, who made this study possible.

\section{References}

Bhagwanani, S. G., Fahmy, D., and Turnbull, A. C. (1972). Lancet, 2, 66. Gluck, L. M., et al. (1971). American fournal of Obstetrics and Gynecology, 109,440 .

Macdonald, H. N., and Isherwood, D. M. (1972). Lancet, 1, 321.

Nelson, G. H. (1972). American fournal of Obstetrics and Gynecology, 98, 1135 .

Warren, C., Allen, J., and Holton, J. B. (1973). Clinica Chimica Acta, 44, 457. Warren, C., Holton, J. B., and Allen, J. (1974). Annals of Clinical Bio-

chemistry. In press.
Whitfield, C. R., and Sproule, W. B. (1972). Lancet, 1, 382.

\title{
Further Studies of Gastric Hypersecretion in Chronic Renal Failure
}

\author{
A. M. M. SHEPHERD, W. K. STEWART, B. THJODLEIFSSON, K. G. WORMSLEY
}

British Medical fournal, 1974, 1, 96-98

\section{Summary}

The effect of medical treatment has been studied in four patients with end-stage renal failure who suffered from severe spontaneous gastric hypersecretion, associated with very low levels of intraduodenal pH in two cases. Atropine decreased the overnight gastric acid output, but the residual acid secretion and duodenal content of acid remained dangerously high in one of the patients. Secretin inhibited the basal gastric secretion of acid in all cases and converted the $\mathrm{pH}$ of the duodenal contents to alkaline. While atropine cannot be used to control the gastric hypersecretion, secretin may prove to be valuable in the therapeutic management of the gastric hypersecretion of patients with chronic renal failure.

\section{University of Dundee, Dundee DD1 4HN}

A. M. M. SHEPHERD, B.SC., M.R.C.P., Registrar, Department of Medicine W. K. STEWART, M.D., F.R.C.P., Senior Lecturer, Department of Medicine W. K.STEWART, M.D., F.R.C.P., Senior Lecturer, Department of Medicine B. THartment of Therapeutics

K. G. WORMSLEY, M.D., F.R.c.P., Consultant Physician, Department of Therapeutics

\section{Introduction}

A previous report (Shepherd et al., 1973) confirmed the finding by Dekkers et al. (1972) that patients with chronic renal failure might suffer from a high incidence of duodenal ulceration, associated with pronounced nocturnal and basal gastric hypersecretion of acid. The present study was undertaken in order to investigate the pathophysiological basis of the duodenal ulceration and of the "spontaneous" gastric hypersecretion in more detail, and to study the effect of potential therapeutic measures on the gastric hypersecretory state.

\section{Methods}

The study involved four male patients who had been undergoing haemodialysis for end-stage renal failure (two chronic glomerulonephritis, one chronic pyelonephritis, and one unidentified chronic renal disease) for 12 to 46 months. Dialysis was carried out for an average of 17 hours a week in two sessions of equal length with Travenol "Ultra-flo 100" disposable coil dialysers.

The investigations of the alimentary tract were carried out between 24 and 48 hours after the preceding haemodialysis. On separate days four different tests were carried out on two of the patients (cases 3 and 4) and three of the tests on the other two patients. Informed consent was obtained for all the procedures. 


\section{TEST SCHEDULES}

1. The patients were fasted from 15.00 hours and were intubated with a double lumen nasogastric tube (Anpro Andersen AN10) at 19.00 hours. Continuous aspiration of nocturnal gastric secretion was carried out from 20.00 to 08.00 hours. The gastric aspirate was pooled, its volume measured, and the acid concentration estimated by titration to $\mathrm{pH} 7 \cdot 0$. No food or drink was taken during the test.

2. Nocturnal gastric secretion was continuously aspirated from 20.00 to 08.00 hours while $0.6 \mathrm{mg}$ atropine sulphate (Antigen, Ltd.) was administered intramuscularly at 20.00 hours, midnight, and 04.00 hours. The 12-hour aspirate was pooled, its volume was recorded, and the acid concentration was measured.

3 (a). A composite four-lumen tube (each component $1 \mathrm{~mm}$ external diameter) was passed under radiological control until the gastric aspiration holes were sited in the antrum and the duodenal aspiration holes at the junction of the second and third parts of the duodenum. Three-millilitre samples each of gastric and duodenal contents were obtained at hourly intervals from 20.00 to 08.00 hours and the $\mathrm{pH}$ and acid or bicarbonate concentrations were measured titrimetrically. (b). From $08 \cdot 00$ to 09.00 hours basal gastric secretion was aspirated. The volume of the aspirate was noted and the acid concentration measured. (c). Each patient then received a continuous intravenous infusion of secretin ( 3 clinical units $\mathrm{kg} / \mathrm{hr}$ ) (G.I.H. Laboratory, Karolinska Institute, Stockholm) in $0.15 \mathrm{M}$ sodium chloride. Gastric and duodenal contents were aspirated continuously for 40 minutes in 10-minute batches. The volumes were measured and acid or bicarbonate concentrations were estimated titrimetrically.

4. Intermittent sampling from the stomach and duodenum was carried out as in $3(a)$, while $0.6 \mathrm{mg}$ atropine sulphate was administered at 20.00 hours, midnight, and 04.00 hours. Three-millilitre samples of gastric and duodenal contents we obtained at hourly intervals and the $\mathrm{pH}$ and acid concentration measured.

\section{Results}

Effect of Atropine on 12-hour Overnight Gastric Secretion.-In all four patients atropine reduced the high level of overnight secretion of acid to significantly lower levels, but the secretion remained very high after atropine in one patient (case 4 ). The reduction in acid output during atropinization was due to a decrease in the volume of the secreted gastric juice, without significant change in acid concentration (table I).

TABLE I-Effect of Atropine on 12-hour Overnight Secretion of Acid

\begin{tabular}{|c|c|c|c|c|c|c|}
\hline \multirow{2}{*}{ Case No. } & \multicolumn{2}{|c|}{$\begin{array}{c}\text { Volume } \\
\text { (ml) }\end{array}$} & \multicolumn{2}{|c|}{$\begin{array}{c}\text { Concentration } \\
(\mathrm{mEq} / \mathrm{l} .)\end{array}$} & \multicolumn{2}{|c|}{$\begin{array}{c}\text { Output } \\
\text { (mEq) }\end{array}$} \\
\hline & Before & After & Before & After & Before & After \\
\hline $\begin{array}{l}1 \\
2 \\
3 \\
4\end{array}$ & $\begin{array}{r}360 \\
690 \\
890 \\
1,580\end{array}$ & $\begin{array}{r}250 \\
205 \\
205 \\
1,020\end{array}$ & $\begin{array}{r}101 \\
91 \\
64 \\
110\end{array}$ & $\begin{array}{r}64 \\
104 \\
56 \\
106\end{array}$ & $\begin{array}{r}36.4 \\
62.5 \\
56.8 \\
173.8\end{array}$ & $\begin{array}{r}16 \cdot 0 \\
21.3 \\
11.5 \\
108.1\end{array}$ \\
\hline
\end{tabular}

Overnight $p H$ in Stomach and Duodenum.-The intragastric $\mathrm{pH}$ was persistently low (pH 0.9 to 1.4 ) throughout the night in three of the patients. One (case 2 ) developed severe duodenogastric reflux between 02.00 and 03.00 hours, after which the gastric contents became, and remained, near-neutral (fig. 1). The duodenal contents were strongly acid in one subject (case 3), whose intraduodenal acid concentration approximately equalled that in his stomach, except from 06.00 hours onwards, when the duodenal contents became neutral. A second patient (case 4) also had acid duodenal contents throughout the night until 05.00 hours, when the duodenal aspirate became neutral. The re- maining two patients had persistently neutral or slightly alkaline (up to $\mathrm{pH} \mathrm{7.5)} \mathrm{duodenal} \mathrm{contents} \mathrm{after} \mathrm{22.00} \mathrm{hours.}$

Effect of Atropine on Overnight $\mathrm{pH}$ in Stomach and Duodenum.-The administration of atropine to the two most severe gastric hypersecretors reduced the concentration of acid in the gastric aspirate in case 3 (median concentration of acid 116, reduced to $72 \mathrm{mEq} / 1$, and $\mathrm{pH} 1 \cdot 1$, increased to 1.8 ) but did not significantly affect the pattern of intragastric $\mathrm{pH}$ in case 4 . The intraduodenal acid concentration was lower during atropinization (maximal concentration of acid 59, instead of $141 \mathrm{mEq} / \mathrm{l}$.) and $\mathrm{pH}$ was higher (lowest $\mathrm{pH} 1.6$, instead of 1.0 ) in case 3 but was not significantly changed by atropine in case 4 (fig. 1) except that the period of duodenal neutralization ranged from 01.00 to 04.00 hours instead of from 05.00 hours onwards.
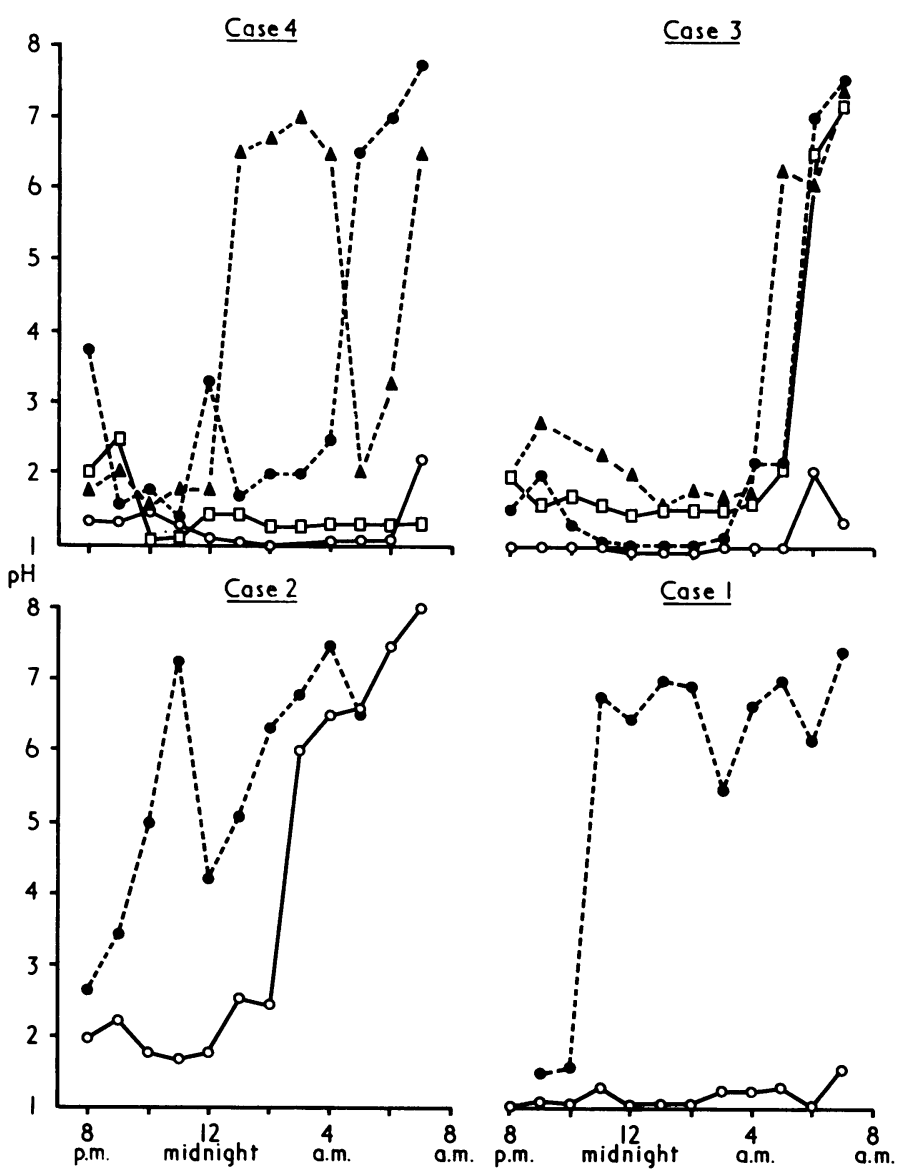

FIG. 1-Nocturnal pH of gastric and duodenal contents. Solid Symbols depict $\mathrm{pH}$ of duodenal contents without $(O)$ and with $(\Delta)$ atropline. The $\mathrm{pH}$ of gastric contents is shown by open symbols-without $(0)$ and with $\left({ }^{\circ}\right)$ atropine, respectively.

Effect of Secretin on Basal Acid Secretion.-In two of the patients the secretion of acid during the basal hour was slight and reflux of duodenal contents completely obscured any residual acid secretion during infusion of secretin (fig. 2). In the other two patients acid secretion decreased markedly, with decreases particularly in the rate of secretion of gastric juice, but not in the concentration of acid in case 4.

TABLE II-Comparison of Bicarbonate and Acid-secretory Capacities

\begin{tabular}{|c|c|c|c|}
\hline Case No. & $\begin{array}{c}\text { Bicarbonate Response to } \\
\text { Secretin } \\
\text { (mEp/hr) }\end{array}$ & Peak & $\begin{array}{l}\text { Acid Response to } \\
\text { Pentagastrin } \\
\text { (mBq/hr)* }\end{array}$ \\
\hline $\begin{array}{l}1 \\
2 \\
3 \\
4\end{array}$ & $\begin{array}{l}37.5 \\
48.9 \\
46.5 \\
50.1\end{array}$ & & $\begin{array}{l}39 \cdot 0 \\
20 \cdot 4 \\
36.9 \\
49 \cdot 5\end{array}$ \\
\hline
\end{tabular}

* From Shepherd et. al. (1973). 
Pancreatic Secretion of Bicarbonate during Infusion of Secretin. - The outputs of bicarbonate in response to secretin were in the higher range of normal (table II).

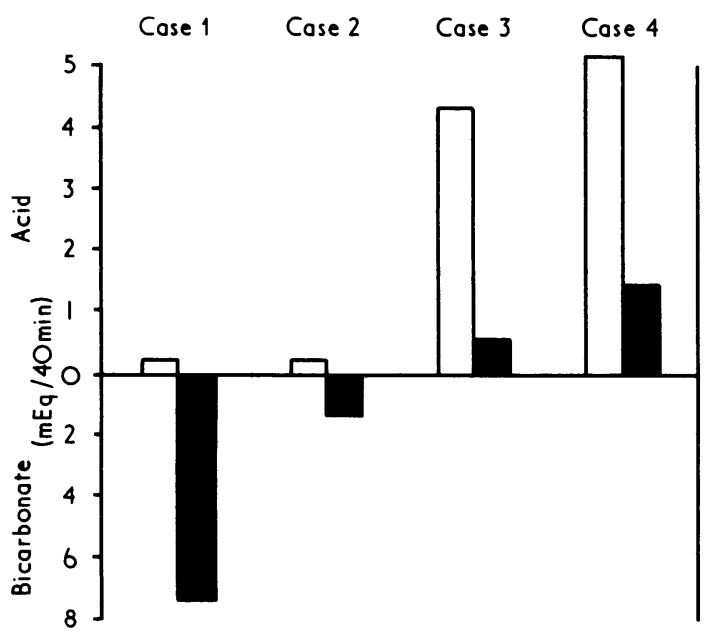

FIG. 2-Effect of secretin on basal gastric acid secretion. Vertical columns represent total amounts of acid or bicarbonate aspirated from stomach in the 40 minutes before (open columns) and the 40 minutes during (solid columns) infusion of secretin.

\section{Discussion}

The present study has shown that the high "spontaneous" acid secretion in four patients with chronic renal failure is associated with low values of $\mathrm{pH}$ and high intraluminal concentration of acid not only in the stomach but also in the duodenum, at least as far as the third part. The very low $\mathrm{pH}$ in the postampullary duodenum in two of our patients is quite abnormal since values of $\mathrm{pH}$ in this part of the duodenum are near-neutral both in normal subjects and in patients with duodenal ulcer (Andersson and Grossman, 1965; Rhodes and Prestwick, 1966; Aynaciyan and Bingham, 1969). Low intraluminal pH of the order found in the present study has been recorded previously only in patients with the Zollinger-Ellison syndrome (Summerskill, 1959; Cook and French, 1968; Go et al., 1970), in whom spontaneous hypersecretion of acid is also associated with a high incidence of duodenal ulceration (Zollinger and Ellison, 1955).

As in normal subjects, patients with duodenal ulcer (Lieber, 1956; Mitchell et al., 1962; Makhlouf et al., 1968), and patients with the Zollinger-Ellison syndrome (Vogel et al., 1967; Cook and French, 1968; Shimoda and Rubin, 1968; Schrumpf et al., 1973), atropine reduced the gastric secretion of acid in our patients. However, despite the overall reduction in overnight secretion of acid during atropinization, the intraluminal $\mathrm{pH}$ in the stomach and duodenum of two of our patients remained very low throughout most of the night, so that anticholinergic drugs seem unsuitable for the therapeutic management of gastric hypersecretory patients with chronic renal failure.

While the basal gastric hypersecretion of patients with the Zollinger-Ellison syndrome is stimulated by intravenous secretin (Isenberg et al., 1972; Bradley and Galambos, 1972; Gallagher and Stening, 1972), the basal secretion of acid in our patients was markedly or completely suppressed by the dose rate of secretin used in the present study. The gastric secretory response to secretin of patients with chronic renal failure therefore qualitatively resembles that of normal subjects, whose basal secretion of acid is also inhibited by high doses of secretin' (Wormsley, 1968 a).

The secretion of bicarbonate in response to secretin was in the high normal range (Wormsley, $1968 \mathrm{~b}$ ) in our patients but not as great as has been reported in patients with the Zollinger-Ellison syndrome (Dreiling and Greenstein, 1972). Though in all our patients the capacity to secrete bicarbonate into the duodenum far surpassed the rate of spontaneous secretion of acid in the same individual and even exceeded the maximal acidsecretory capacity of their stomachs, the contents of the postampullary duodenum of two of our patients were nevertheless strongly acid. This finding indicates either that bicarbonate secretion is not stimulated by acid in the small intestine, perhaps because the small intestinal receptors which activate the bicarbonate-secretory response to acid do not function normally after prolonged exposure to excessive amounts of acid, or that the effect of the endogenous stimulus on the pancreas is inhibited by the abnormal $\mathrm{pH}$ of the intraluminal contents of the duodenum. However, it was evident that intravenously-infused secretin stimulated the secretion of bicarbonate into the duodenum and also inhibited the spontaneous gastric secretion of acid in our hypersecretory patients, so that exogenous secretin may prove to be useful in controlling the tendency to duodenal ulceration in patients with chronic renal failure, particularly during the dangerous period after renal transplantation when serious gastrointestinal complications such as haemorrhage and perforation tend to occur (Lewicki et al., 1972).

In conclusion, it seems probable that in some patients with chronic renal failure ulceration of the duodenum is related to abnormally great concentrations of acid in the duodenum. The abnormal duodenal content of acid is associated with, and its injurious effects are aggravated by, an impaired pancreatic response to the acid. While anticholinergic drugs do not appear to be therapeutically effective in controlling the excessive gastric secretion and duodenal content of acid, there may be a place for secretin in the treatment of these patients, particularly if longacting preparations of secretin (Classen et al., 1973) become commercially available.

K.G.W. gratefully acknowledges a research grant from the Scottish Hospital Endowments Research Trust.

Requests for reprints should be addressed to: Dr. K. G. Wormsley, Clinical Investigation Unit, Maryfield Hospital, Dundee DD4 7TL, Scotland.

\section{References}

Andersson, S., and Grossman, M. I. (1965). Gastroenterology, 49, 364. Aynaciyan, A. V., and Bingham, J. R. (1969). Gastroenterology, 56, 476. Bradley, E. L., and Galambos, J. T. (1972). American Fournal of Digestive Diseases, 17, 939 .

Classen, M., Koch, H., Domschke, W., and Demling, L. (1973). Acta Hepato-Gastroenterologia, 20, 90 .

Cook, H. B., and French, A. B. (1968). American fournal of Digestive Diseases, 13, 191 .

Dekkers, C. P. M., Endeman, J. H., Poen, H., Jessurun, R. F. M., and Ten Thije, O. J. (1972). Archives Franfaises des Maladies de l'Appareil Digestif, 61, 273c

Dreiling, D. A., and Greenstein, A. (1972). American fournal of Gastroenterology, 58, 66.

Gallagher, N. D., and Stening, G. F. (1972). Australian and New Zealand Fournal of Medicine, 4, 393 .

Go, V. L. W., Poley, J. R., Hofmann, A. F., and Summerskill, W. H. J. (1970). Gastroenterology, 58, 638.

Isenberg, J. I., Walsh, J. H., Passaro, E., jun., Moore, E. W., and Grossman, M. I. (1972). Gastroenterology, 62, 626.

Lewicki, A. M., Saito, S., and Merrill, J. P. (1972). Radiology, 102, 533.

Lieber, C. S. (1956). Acta Gastro-Enterologica Belgica, 19, 819.

Makhlouf, G. M., McManus, J. P. A., and Knill, J. R. (1968). Gastro-

Mitchell, R. D., Hunt, J. N., and Grossman, M. I. (1962). Gastroenterology, 43,400 .

Rhodes, J., and Prestwick, C. J. (1966). Gut, 7, 509.

Schrumpf, E., Petersen, H., Berstad, A., Myren, J., and Rosenlund, B. (1973). Scandinavian fournal of Gastroenterology, 8, 145.

Shepherd, A. M. M., Stewart, W. K., and Wormsley, K. G. (1973). Lancet, $1,1357$.

Shimoda, S. S., and Rubin, C. E. (1968). Gastroenterology, 55, 695.

Summerskill, W. H. J. (1959). Lancet, 1, 120.

Vogel, R. M., Weinstein, L. D., Herskovic, T., and Spiro, H. M. (1967). Annals of Internal Medicine, 67, 816.

Wormsley, K. G. (1968 a). Scandinavian Fournal of Gastroenterology, 3, 632. Wormsley, K. G. (1968 b). Gastroenterology, 54, 197.

Zollinger, R. M., and Ellison, E. H. (1955). Annals of Surgery, 142, 709. 